\title{
LA LEGISLACIÓN PATRIMONIAL DE LA PROVINCIA DE SAN LUIS. CONSIDERACIONES SOBRE CUESTIONES VINCULADAS CON LA IDENTIDAD, LA PARTICIPACIÓN Y LA SUSTENTABILIDAD SOCIO- CULTURAL.
}

\section{HERITAGE LEGISLATION OF SAN LUIS PROVINCE. CONSIDERATIONS CONCERNING ISSUES RELATED TO IDENTITY, PARTICIPATION AND SOCIO-CULTURAL SUSTAINABILITY.}

\author{
María Vanesa Giacomassoํํ y María Luz Endere²
}

\begin{abstract}
1PATRIMONIA- INCUAPA (UE CONICET-UNICEN), Facultad de Ciencias Sociales, Universidad Nacional del Centro de la Provincia de Buenos Aires.

Email: vanegiaco05@gmail.com -

2PATRIMONIA- INCUAPA (UE CONICET-UNICEN), Facultad de Ciencias Sociales, Universidad Nacional del Centro de la Provincia de Buenos Aires. Email: mendere@soc.unicen.edu.ar
\end{abstract}

Presentado: 12/03/2019

Aceptado: 07/11/2019

\section{Resumen}

En este trabajo se analizan las principales conceptualizaciones sobre el patrimonio cultural en la provincia de San Luis a partir de un relevamiento y análisis de su normativa legal, provincial y municipal y su relación con los marcos regulatorios nacionales, así como también a partir de planes y programas provinciales relacionados con la temática. El objetivo central consiste en identificar los aspectos más importantes asociados con el patrimonio e indagar sobre el modo en que se abordan cuestiones claves como son la identidad, la participación ciudadana y la sustentabilidad socio-cultural. A través de este análisis se pretende discutir los enfoques y perspectivas predominantes sobre el patrimonio cultural en la provincia a la luz de la normativa nacional marco y los objetivos del desarrollo sustentable. Esperamos que este trabajo permita profundizar la reflexión sobre estas cuestiones y constituya un aporte en vista a futuros proyectos de gestión patrimonial en la región.

Palabras clave: legislación, patrimonio cultural, identidad, participación, sustentabilidad sociocultural.

\section{Abstract}

In this paper, the main conceptualizations about cultural heritage in the province of San Luis are analyzed through the analysis of their legal, provincial and municipal regulations and their relationship with national regulatory frameworks, as well as through the study if provincial plans and programs related to this topic. The main objective is to identify the most important aspects associated with heritage and to investigate the way in which key issues such as identity, citizen participation and socio-cultural sustainability are 
addressed. Through this analysis, we intend to discuss prevailing approaches and perspectives on cultural heritage in this province in light of the national legal framework and the objectives of sustainable development. We hope that this paper will deepen the reflection on these issues and constitute a contribution in view of future heritage management projects in the region.

Keywords: legislation, cultural heritage, identity, participation, sociocultural sustainability.

\section{Introducción}

En las últimas décadas, en la provincia de San Luis, el patrimonio cultural ha jugado un papel cada vez más significativo en la sanción de un conjunto de normas y la creación de programas que fueron instaurados en la región, en el marco de políticas públicas que buscan posicionar a la cultura entre los ejes primordiales de desarrollo provincia (1). Esto se manifiesta tanto en la Ley de Patrimonio Cultural de la provincia de 2006 y otras normativas relacionadas de carácter más general (e.g. Ley Provincial $N^{\circ}$ II-0872-2013 -Plan Maestro de las Culturas- y Ley Provincial VIII - 0722 - 2010 - Plan Maestro de Turismo) y más específicas (e.g. decretos que declaran bienes como pertenecientes al patrimonio cultural de la provincia). De ellos se derivaron programas, como el Programa Cultura y el Subprograma de Patrimonio Histórico y Cultural, los cuales desde su creación han buscado "contribuir a la sustentabilidad social, económica y ambiental en el ámbito de la provincia"(2). Esto se complementa con una continua difusión en los medios de comunicación regionales (3) sobre acciones llevadas a cabo en el marco de dichos programas, lo cual evidencia un interés en la visibilización de "lo cultural" que se perfila, además, como eje transversal para alcanzar la sustentabilidad de la región en sus diversas dimensiones.

En este marco, el objetivo de este trabajo consiste en realizar un análisis de estos documentos oficiales para identificar el modo en que el Estado provincial concibe la cultura y el patrimonio, con especial atención en tres nociones claves: la identidad cultural, la participación ciudadana y la sustentabilidad socio-cultural. Para este estudio, estos tópicos se consideran de relevancia desde una perspectiva que se sustenta en la importancia que tiene el patrimonio cultural en la construcción de las identidades y que se centra en un enfoque de gestión participativa del mismo, dentro del cual se reconoce el involucramiento comunitario como condición indispensable para el diseño y la implementación de proyectos que busquen ser sustentables. Es por ello que se considera oportuno relevar cómo dichos aspectos -considerados centrales- son instrumentalizados en las normas y programas regionales, discutir su operatividad y generar a la postre un análisis que sirva de insumo para el diseño y construcción de futuros instrumentos de gestión cultural en la provincia. 


\section{Patrimonio, Identidad y Sustentabilidad socio-cultural}

La noción de patrimonio es importante para la cultura de un grupo o región en cuanto forma parte de su capital social y cultural y contribuye al fortalecimiento de las identidades. En su sentido más amplio, está compuesto por bienes, tanto tangibles como intangibles, que los grupos humanos heredan del pasado, construyen en el presente y transmiten a las futuras generaciones para su uso y beneficio (Bonfil Batalla 2004; García Canclini 1999, Prats 2005, 2007; Rosas Mantecón 1998, 2005; UNESCO 2014). En forma de legado o "bien común" el patrimonio es un conjunto de elementos seleccionados que una sociedad determinada valora y tiende a privilegiar, por encima de otros, presentándolos como símbolos de su cultura e identidad. Por eso se considera al patrimonio cultural estrechamente ligado con la construcción identitaria y la memoria colectiva de los grupos, lo que conduce a la necesidad de inventariarlo, conservarlo y protegerlo (Giménez 2005). En este marco resultan claves los lineamientos políticos del Estado y sus propuestas de gestión en torno al manejo del patrimonio, como así también la participación que tienen en dicho proceso las propias comunidades. Esta dimensión se constituye en otro aspecto fundamental en cuanto toda persona tiene derecho de participar en la vida cultural, tal como consagra el art. 27 de la Declaración Universal de Derechos Humanos. Cabe destacar además derechos consagrados en otros instrumentos internacionales que tienen rango constitucional en nuestro país, como el Pacto Internacional de Derechos Económicos, Sociales y Culturales, a través del cual se le solicita a los Estados que reconozcan el derecho de toda persona a participar en la vida cultural de la comunidad (Artículo 15.1), así como la Convención Americana sobre Derechos Humanos (conocida como Pacto de San José de Costa Rica) que incorpora el derecho a participar en asuntos públicos (art. 23), así como demás derechos económicos, sociales y culturales reconocidos en el art. 26 y concordantes.

El reconocimiento del derecho a la participación en la vida cultural repercute en las formas de acceso e inclusión de los diversos actores y, consecuentemente, condiciona el desarrollo y sostenibilidad de los proyectos y acciones culturales implementadas. La participación, además, fomenta no sólo sentidos de pertenencia, de integración y responsabilidad en relación con el patrimonio, sino que promueve la acción colectiva y la democratización en asuntos de interés común (UNESCO 2014). El patrimonio cultural genera, activa $\mathrm{y}$, a su vez, se asocia con múltiples significaciones y valores tales como el artístico, el arquitectónico, el científico, histórico, educativo. Frecuentemente, adquiere también valor económico, en la medida en que los bienes patrimoniales pueden convertirse, por ejemplo, en bienes de consumo turístico que atraen a diversidad de visitantes.

Por todo lo anterior, el concepto de patrimonio tiene en la actualidad una relación cada vez más directa con la sustentabilidad o desarrollo regional sustentable que, concebido de manera integral, busca satisfacer las necesidades de los grupos humanos del presente sin comprometer las de las generaciones futuras. La sustentabilidad es entendida desde, al menos, cuatro dimensiones: económica, que promueve un desarrollo económicamente eficiente y equitativo; ecológica, que implica preservar la integridad de los recursos y procesos naturales; social y cultural, que promueve el 
mantenimiento del sistema de valores, prácticas y símbolos de identidad, igualdad y bienestar humano; y política, que privilegia la regulación pública como política de Estado (Guimarães 2003). En este marco, el diseño de las políticas de gestión cultural en la provincia de San Luis tiene vinculación con la dimensión socio-cultural de la sustentabilidad, motivo por el cual interesa, en este estudio, un análisis de dicha perspectiva y el modo en que son contempladas en las norma y instrumentos de gestión referidas a la temática.

Cabe destacar que la Agenda 2030 para el Desarrollo Sostenible, aprobada en 2015 por los Estados Miembros de la Organización de las Naciones Unidas (ONU), entre ellos Argentina, establece un plan de acción a partir de 17 objetivos del desarrollo sostenible (ODS) de carácter integrado que conjugan las dimensiones económica, social y ambiental para construir sociedades a favor de las personas, el planeta y la prosperidad (Wood et al. 2018). El objetivo 11 apunta a lograr ciudades y comunidades sostenibles, siendo la cultura y, por ende, el patrimonio cultural, uno de los aspectos a considerar. En efecto, la meta 11.4 del objetivo 11 establece la necesidad de "redoblar los esfuerzos para proteger y salvaguardar el patrimonio cultural y natural del mundo".

Tener en vista estos objetivos permite identificar cuestiones prioritarias en las políticas para la gestión del patrimonio cultural. De ello se desprende la importancia de considerar la sustentabilidad socio-cultural, que apunta a mantener y fortalecer los valores identitarios que permiten la reproducción del tejido social y garantizan la integración nacional a lo largo de su historia (García y Priotto 2008:11).

\section{Marco legal sobre el patrimonio cultural en Argentina}

La protección del patrimonio cultural en Argentina se sustenta, por un lado, en el marco normativo aplicable y por otro en la gestión administrativa que deben llevar a cabo las autoridades competentes en uso de sus facultades. En relación con el marco legal, cabe destacar que el patrimonio cultural y natural, está contemplado en la Constitución Nacional en la que se establece que "las autoridades proveerán a la preservación del patrimonio natural y cultural" (...). Asimismo, se especifica que "corresponde a la Nación dictar las normas que contengan los presupuestos mínimos de protección, y a las provincias, las necesarias para complementarlas, sin que aquellas alteren las jurisdicciones locales" (art. 41). Es decir que el Estado Nacional debe dictar las "leyes marco", que serán complementadas por las leyes provinciales.

Cabe destacar que Ley Nacional del Ambiente 25.675 establece “los presupuestos mínimos para el logro de una gestión sustentable del ambiente y su implementación para el desarrollo sustentable". Entre sus objetivos incluye el de: "Asegurar la preservación, conservación, recuperación y mejoramiento de la calidad de los recursos ambientales, tanto naturales como culturales, en la realización de las diferentes actividades antrópicas" y "fomentar la participación social en los procesos de toma de decisión" (art. 2 inc. a y c). 
En relación con el patrimonio cultural, si bien no se ha sancionado aún una ley de presupuestos mínimos, existen dos leyes nacionales que sirven de marco regulatorio general. Ellas son la Ley de Patrimonio Histórico y Artístico $\left(\mathrm{N}^{\circ} 12665 / 40\right.$ modificada por la ley 27.103/15) que protege a aquellos sitios que han sido declarados monumentos, lugares o bienes históricos nacionales y la Ley de Protección de Patrimonio Arqueológico y Paleontológico ( $\left.\mathrm{N}^{\circ} 25.743 / 03\right)$ que lo regula de manera específica (Berberián 2009; Calabrese 2012; ver también Endere y Rolandi 2007; Guráieb y Frère 2008). Cabe mencionar, además, la Ley de Régimen de Registro del Patrimonio Cultural (Ley No 25.197/99) que prevé la creación de un Registro Nacional de Bienes Culturales. Esta norma no ha sido reglamentada, razón por la cual no es operativa.

Es importante remarcar que los bienes culturales poseen diferente status jurídico en Argentina. Por un lado, están los yacimientos arqueológicos y paleontológicos que pertenecen al dominio público del estado desde el momento de su descubrimiento. Esto implica que son inajenables, inembargables e imprescriptibles (art. 237 del Código Civil y Comercial Unificado -CCCU-). Por otro, se ubica el resto de los bienes culturales que pueden ser de dominio público o privado y que requieren de una declaratoria nacional o provincial para formar parte del Patrimonio cultural. Este tipo de declaratorias no altera la titularidad del bien, a menos que se disponga de su expropiación por ley y se abone la correspondiente indemnización al propietario. No obstante, se suelen prever diferentes medidas restrictivas del dominio (Endere 2009; Endere y Colombato 2017).

Cabe destacar que, en los términos de la Ley 12.665 se han declarado en la provincia de San Luis monumentos y lugares históricos nacionales (4), los cuales deben ser gestionados, de manera concurrente, por la Comisión Nacional de Monumentos, de Lugares y de Bienes Históricos y por las autoridades provinciales competentes (ver Tabla 1).

Asimismo, Argentina ha ratificado las principales convenciones internacionales en la materia, tales como la Convención para la Protección de los Bienes Culturales en caso de Conflicto Armado (La Haya, 1954) ratificada por Ley 23.618/1988; la Convención sobre Medios para Prohibir y Prevenir la Importación, Exportación y Transferencia Ilícita de Bienes Culturales (Roma, 1970) ratificada por Ley 19.943/72; la Convención para la Protección del Patrimonio Natural y Cultural (París, 1972) ratificada por Ley 21.836/78; la Convención de UNIDROIT (Roma 1995) ratificada por Ley 25.257/2000; la Convención sobre la Protección del Patrimonio Cultural Subacuático (París 2001) ratificada por Ley 26.556/09; la Convención para la Salvaguardia del Patrimonio Cultural Inmaterial (París, 2003), ratificada por Ley 26.118/06; la Convención sobre la Protección y Promoción de la Diversidad de las Expresiones Culturales (París, 2005) ratificada por Ley 26.305/07, además de la Convención de San Salvador sobre defensa del Patrimonio, ratificada por Ley 25.568/02. Cabe destacar además que Argentina es 
Estado miembro de la Convención Relativa a los Humedales de Importancia Internacional especialmente como Hábitat de Aves Acuáticas (Ramsar, 1971) (ratificada por Ley $\mathrm{N}^{0}$ 23.919) (5).

\begin{tabular}{|c|c|c|c|}
\hline Zona & Bien Declarado & Categoría & Norma \\
\hline San Luis & $\begin{array}{l}\begin{array}{l}\text { Aguada de } \\
\text { Pueyrredón }\end{array} \\
\text { Esc. De Juan Pascal } \\
\text { Pringles }\end{array}$ & $\begin{array}{l}\text { Lugar histórico } \\
\text { Monumento } \\
\text { Histórico Nacional }\end{array}$ & $\begin{array}{l}\text { Decreto } \\
107512 / 1941 \\
\text { Decreto } \\
769 / 2019\end{array}$ \\
\hline $\begin{array}{l}\text { Municipio de Juana } \\
\text { Koslay (Dpto. J. M. de } \\
\text { Pueyrredón) }\end{array}$ & $\begin{array}{l}\text { Campamento de las } \\
\text { Chacras }\end{array}$ & Lugar Histórico & $\begin{array}{l}\text { Decreto } \\
107512 / 1941\end{array}$ \\
\hline Merlo & $\begin{array}{l}\text { Capilla del Rosario } \\
\text { de Piedra Blanca }\end{array}$ & $\begin{array}{l}\text { Monumento } \\
\text { Histórico }\end{array}$ & $\begin{array}{l}\text { Decreto } \\
2335 / 1961\end{array}$ \\
\hline $\begin{array}{l}\text { Pedernera (Dto de Gral. } \\
\text { Pedernera) }\end{array}$ & $\begin{array}{l}\text { Iglesia San José del } \\
\text { Morro }\end{array}$ & $\begin{array}{l}\text { Monumento } \\
\text { Histórico }\end{array}$ & $\begin{array}{l}\text { Decreto } \\
1456 / 1981\end{array}$ \\
\hline $\begin{array}{l}\text { San Francisco del Monte } \\
\text { de Oro }\end{array}$ & $\begin{array}{l}\text { Escuela de San Fco. } \\
\text { del Monte de Oro }\end{array}$ & $\begin{array}{l}\text { Monumento } \\
\text { Histórico }\end{array}$ & $\begin{array}{l}\text { Decreto } \\
107.512 / 1941 \\
\end{array}$ \\
\hline Cuidad de San Luis & $\begin{array}{l}\text { Cabildo de la } \\
\text { Ciudad de San Luis }\end{array}$ & Lugar Histórico & $\begin{array}{l}\text { Decreto 1456/ } \\
1981\end{array}$ \\
\hline Ciudad de San Luis & $\begin{array}{l}\text { Catedral de la } \\
\text { Ciudad de San Luis }\end{array}$ & Lugar Histórico & $\begin{array}{l}\text { Decreto } \\
30 / 1975\end{array}$ \\
\hline Ciudad de San Luis & $\begin{array}{l}\text { Tumba del Cnel. } \\
\text { Juan P. Pringles }\end{array}$ & Sepulcro & $\begin{array}{l}\text { Decreto } \\
1399 / 1974\end{array}$ \\
\hline Cuidad de San Luis & $\begin{array}{l}\text { Convento de Santo } \\
\text { Domingo }\end{array}$ & Lugar Histórico & $\begin{array}{l}\text { Decreto } \\
1456 / 1981\end{array}$ \\
\hline Villa Mercedes & $\begin{array}{l}\text { Tumba del Tte. Gral. } \\
\text { J. E. Pedernera }\end{array}$ & Sepulcro & $\begin{array}{l}\text { Decreto } \\
8435 / 1972\end{array}$ \\
\hline
\end{tabular}

Tabla 1. Bienes patrimoniales de San Luis declarados como Monumentos, Lugares o Bienes culturales de la Nación en el marco de la Ley No 12.665.

En relación con la participación ciudadana, la Constitución Nacional, en el art 75 inc. 17 contempla "la participación de los pueblos indígenas en la gestión de los recursos naturales y demás intereses que los afecten". Asimismo, el Código Civil y Comercial establece, en el art. 240 límites al ejercicio de los derechos individuales sobre los bienes al contemplar que "El ejercicio de los derechos individuales sobre los bienes (...) debe ser compatible con los derechos de incidencia colectiva. Debe conformarse a las normas del derecho administrativo nacional y local dictadas en el interés público y no debe afectar el funcionamiento ni la sustentabilidad de los ecosistemas de la flora, la fauna, la biodiversidad, el agua, los valores culturales, el paisaje, entre otros, según los criterios previstos en la ley especial". A su vez, el art. 241 especifica que "Cualquiera sea la jurisdicción en que se ejerzan los derechos, debe 
respetarse la normativa sobre presupuestos mínimos que resulte aplicable". Estos artículos si bien requieren una ley especial que los regule marcan un cambio normativo importante y una tendencia a favor de los derechos de incidencia colectiva y el interés público vinculados con la sustentabilidad y los valores culturales entre los que se incluye el patrimonio cultural (Endere y Colombato 2017).

Este conjunto de instrumentos jurídicos brinda un marco normativo a partir del cual las provincias deben dictar normas complementarias para implementarlas adecuándose a las necesidades y particularidades locales, al mismo tiempo que realizar las gestiones políticas pertinentes para su cumplimentación.

\section{Marco legal de la provincia de San Luis}

La Constitución Provincial de 1987 (6) establece, en relación con el patrimonio cultural y natural de la región que "las riquezas pre-históricas, históricas, artísticas y documentales, así como el paisaje natural en su marco ecológico, forma parte del acervo de la provincia que el estado debe tutelar, pudiendo decretar las expropiaciones necesarias para su defensiva y prohibir la exportación o enajenación de las mismas, asegurando su custodia y conservación" (art. 68). En este sentido, se reconoce la función del Estado de intervenir en la salvaguardia de los bienes que sean considerados patrimonio provincial.

Cabe destacar que la Ley de Yacimientos Paleontológicos y Arqueológicos No II0062-2004 (5740) sancionada en 2004 declaró de interés científico a los Yacimientos Arqueológicos de la provincia con arte rupestre (ver Tabla 2).

\begin{tabular}{|l|l|}
\hline Departamentos & \multicolumn{1}{|c|}{ Yacimientos } \\
\hline Ayacucho & $\begin{array}{l}\text { Rodeo de Cadenas, Piedra Blanca, Quebrada del Río, Quebrada de } \\
\text { Bayos. }\end{array}$ \\
\hline Chacabuco & El Algarrobal \\
\hline Pringles & $\begin{array}{l}\text { Arroyo Saladillo, Inti Huasi, Cerro Sololasta, Quebrada del } \\
\text { Durazno, Cañada Honda, La Angostura, Laguna Brava, Los } \\
\text { Morteritos, El Sauce, Quebrada Chiquero, Río Quinto, Paso } \\
\text { Chacras }\end{array}$ \\
\hline Junín & Quebrada Cautana \\
\hline Pedernera & Santa Mercedes \\
\hline San Martín & $\begin{array}{l}\text { Las Lagunas, Arroyo Barro, Cañada del Ají, Estancia Vieja, } \\
\text { Moyano, La Cieneguita, Las Huertas, El Chorro, Los Pozos, El } \\
\text { Divisadero, Puerta del Sol, Cañada Larga, Cañada Víbora, La } \\
\text { Estampa, Las Lagunitas, La Ciénaga, Peñón Colorado, Las } \\
\text { Cavernas, Mesilla del Cura }\end{array}$ \\
\hline Cuchi Corral \\
\hline
\end{tabular}

Tabla 2. Yacimiento arqueológicos con arte rupestre declarados por la provincia. 
En 2006, la provincia sancionó la Ley de Patrimonio Cultural N II-0526 por la cual se adhirió al régimen de Ley Nacional No 25.743 de Protección del Patrimonio Arqueológico y Paleontológico. Es importante considerar los aspectos que señala como prioritarios al momento de desarrollar medidas relativas al patrimonio. En su artículo 1, indica que la finalidad de la ley es la de "implementar la custodia, preservación y expansión del patrimonio cultural [...] a la vez que consolidar la inescindible función social del mismo", para lo cual la autoridad de aplicación tiene por misión "fomentar y facilitar el acceso de todos los habitantes al patrimonio cultural" (art. 9) y al "libre conocimiento público de los Bienes Culturales" (art. 77). Por su parte, entre los componentes del patrimonio cultural se incluyen tanto los bienes inmuebles, como muebles que revistan un interés prehistórico, histórico, arqueológico, paleontológico, antropológico, etnológico, documental, bibliográfico, artesanal, artístico, científico y técnico, así como las simbolizaciones o representaciones inmateriales, que testimonien y perpetúen el sustrato histórico-cultural de la provincia de San Luis o de la Región de Cuyo (art. 2).

Como puede observarse, esta norma comprende al patrimonio cultural en su totalidad, incluyendo los componentes tangibles e intangibles y considerando las múltiples valoraciones asociadas al mismo (ver Giacomasso y Endere 2016).

Cabe destacar el correlato que esta ley tiene con la Ley Nacional 25.743 ya que estipula tanto la organización de un registro de yacimientos, colecciones y objetos provinciales (art. 13 y 14), como la obligatoriedad de contar con una autorización previa para efectuar prácticas de prospección e investigaciones que involucren los bienes mencionados (art. 38). Asimismo, establece un régimen de sanciones que se basa en las penalidades dispuestas en el art. 38 de la referida ley nacional. La norma provincial también hace explícita las funciones que reconoce dicha normativa nacional en materia de medidas restrictivas al dominio privado (art. 79), autorizaciones excepcionales para tenencia temporaria de colecciones, con razones justificadas de interés social, antes de su incorporación al museo provincial (art. 44 y 45) y suspensión de obras cuando las mismas afecten la seguridad, preservación y conservación del patrimonio cultural (art. 82 inc. c).

En cuanto a los aspectos que también son de relevancia para este análisis, como la vinculación del patrimonio cultural con la identidad y la participación, la ley de San Luis no introduce cuestiones relativas a la construcción de la identidad y la memoria regional en lo que se denomina la "preservación" y "expansión" patrimonial. Estos conceptos están ausentes, así como el de participación comunitaria. Si bien se garantiza "el acceso y conocimiento público" de todos los pobladores al patrimonio cultural, no se contemplan mecanismos concretos que den lugar a la generación de procesos de gestión participativa (ver Caraballo Perichi 2012) que permitan el involucramiento de la comunidad en la toma de decisiones sobre la selección de los bienes y su protección. Asimismo, la alusión a la "función social" del patrimonio tampoco se traduce en los usos, beneficios y/o su contribución al desarrollo sustentable que este podría suscitar para la población local. 
Cabe mencionar que esta norma provincial se completa con otras leyes de menor incidencia en el caso, pero que merecen destacarse porque se vinculan con el patrimonio histórico-documental, como la Ley N ${ }^{\circ}$ II-0531/06 que crea un Sistema Provincial de Bibliotecas. Esta norma tiene por objetivo principal la conservación y organización del patrimonio de documentos bibliográficos, audiovisuales y afines y su puesta al servicio de la comunidad, a través de bibliotecas abiertas para todos sin discriminación religiosa, política, económica o social (art. 2). Esta ley resulta de interés en tanto reconoce el derecho al acceso público a documentos que puedan revestir un valor patrimonial, tanto para la población local como a los fines de la investigación en el área.

A diferencia de la Ley de Patrimonio Cultural, en esta norma se manifiesta expresamente el interés por poner los materiales al "servicio de la comunidad" para su propio "desarrollo" (art. 2 inc. 1 y 2) y "garantizar el ejercicio del derecho a la información, el acceso a la cultura y a la educación permanente (...) sobre temas locales y regionales que permitan el rescate de la identidad sanluiseña, la consulta y la recreación" (art. 3 inc. 1).

Cabe destacar que los pueblos indígenas no son contemplados en ninguna de las normas de patrimonio mencionadas, pese a las políticas desarrollada por el gobierno provincial en las últimas décadas de reconocimiento a los pueblos indígenas Huarpe y Ranquel considerados preexistentes en el territorio. En este marco, fueron restituidas tierras a dichas comunidades (ver Ley V-0600-2007).

\section{Patrimonio, turismo y sustentabilidad}

Las disposiciones legales bajo análisis se sancionaron en la primera década del siglo XXI, época en la cual la noción de sustentabilidad no estaba todavía incorporada en el discurso, como si ocurre en la normativa provincial aprobada en la segunda década, en la cual se comienza a considerar esta perspectiva. Se trata de leyes que crean planes de gobierno tendientes al desarrollo provincial, tales como el Plan Maestro de Turismo (Ley N VIII-0722-2010) y el Plan Maestro de las Culturas 2013-2023 (Ley N II-0872-2013).

En relación con el primero, es claro el objetivo respecto a "contribuir a la sustentabilidad económica, ambiental y social de la Provincia de San Luis (...) a través de la promoción del turismo (...), determinando los mecanismos necesarios para la creación, conservación, protección y aprovechamiento de los recursos y (...) estableciendo los mecanismos de participación y concertación de los sectores público y privado en la actividad (art. 2). Asimismo, entre los principios rectores que señala la ley se encuentran la "Promoción del desarrollo regional equilibrado", la "Valorización y preservación del patrimonio natural y cultural de la Provincia" y la "Promoción de la integración social", entre otros aspectos relativos a la estructura económica y la innovación productiva (art. 3). Es interesante cómo se definen en dicha norma las zonas turísticas del territorio de San Luis que se caracterizan por poseer "un criterio de integración de recursos culturales y naturales y de afianzamiento de la identidad provincial". Estas se corresponden con: a) Zona de los Inicios de la Tierra (Norte de Este a Oeste que incluye el Parque Nacional Sierra de Las Quijadas y el Parque Provincial Bajo de Véliz, entre otros), b) Zona de Serranías, Historia y Minerales (Centro de Este a 
Oeste que incluye Sistemas montañosos, Sitios históricos, áreas urbanas, manifestaciones culturales, Yacimientos mineros metalíferos, no metalíferos y rocas de aplicación y c) Zona de Originarios, Venados y Lagunas (Sur de Este a Oeste que incluye Pueblos Originarios; Explotaciones agrícolas-ganaderas; Lagunas, pastizales y venados) (art. 8). En estas áreas no se mencionan los sitios arqueológicos como bienes de interés turístico, pese a que la Ley de Patrimonio Cultural es anterior a esta norma y se adecua a la Ley Nacional de Patrimonio Arqueológico y Paleontológico, por lo que cuestiones referidas al turismo y la arqueología deberían haber sido consideradas.

Cabe destacar que esta ley aprueba el Plan Maestro de Turismo 2010-2020, que incluye diversos programas para su ejecución y seguimiento dentro de los que se destacan el de "Valorización Patrimonial" para la "identificación, planificación, puesta en valor, gestión y protección" de los recursos naturales y culturales (art. 9. b) y el referido a la "Participación y Capacitación", orientado a "capacitar a todos los actores públicos y privados" y a la "concientización y sensibilización de la comunidad" (art. 9.e). En cuanto a la participación la ley también reconoce entre sus presupuestos, y a través de las funciones del Consejo Asesor Provincial de Turismo (art. 17), la importancia de "Fortalecer las relaciones con las comunidades y articular programas de participación ciudadana" (art. 19b).

En este sentido, la perspectiva turística aparece directamente vinculada con el patrimonio cultural y natural y con la necesidad de su valorización y preservación a partir de gestiones que, entre otras cosas, se orientan a la "sensibilización" y "participación" de la población local con respecto a los recursos provinciales. En este punto se destaca el uso de los conceptos de "comunidad", "identidad" e "integración social", los cuales aparecen articulados a estos procesos; y también el de "sustentabilidad", en su dimensión económica, ambiental y social, como objetivo central a cumplir a partir de los programas que establece la provincia.

Por otro lado, el Plan Maestro de las Culturas 2013-2023, aprobado por Ley II-08722013, tiene como horizonte promover el "desarrollo cultural de todos los habitantes de la provincia de San Luis (...) con eje en el fortalecimiento de una identidad puntana inclusiva y respetuosa de la diversidad cultural" (p. 7). Esta idea central de desarrollo cultural se afirma en el concepto de sustentabilidad que, como complemento del desarrollo económico, enfatiza la necesidad de "sostener todas las formas de capital y recursos (físicos, humanos, financieros, ambientales) para asegurar las necesidades de futuras generaciones" y plantea la importancia de atender a "la incidencia de los factores culturales sobre la calidad de vida" (p. 24).

Este plan, además de su objetivo macro de fortalecer la identidad y diversidad cultural de la provincia, propone estrategias para fomentar las "industrias creativas" como emprendimientos culturales. Asimismo se menciona la necesidad de contar con "gestión, infraestructura y participación ciudadana, orientadas a ampliar la democracia cultural e impulsar un sector cultural dinámico" (7). En este 
punto, el plan hace un fuerte hincapié en la democratización tendiente a "respetar e incentivar todas las expresiones de la cultura"; asimismo se menciona la importancia del "acceso igualitario a los medios de creación, producción, difusión, exhibición y consumo/participación de bienes y servicios culturales" y al involucramiento de los ciudadanos como "participantes activos en el ciclo de las políticas culturales" (p. 24). La participación, por lo tanto, aparece como un factor decisivo dentro de las intenciones políticas que la provincia persigue para la gestión de sus recursos culturales.

Cabe destacar que algunas de las principales metas del Plan refieren a la revalorización de las "tradiciones, folklore, historia y costumbres populares"; así como al fortalecimiento de "la identidad de los pueblos originarios, preservando y recuperando su cultura ancestral" y se hace mención a las Comunidades Ranquel y Huarpe, presentes en la provincia. La identidad puntana o "puntanidad" (8) es asimismo definida en dicho plan como "plural y diversa" que tienen sus raíces en las culturas ancestrales y se proyectó hacia el futuro, incorporando las expresiones de las nuevas culturas emergentes.

Finalmente se enfatiza la necesidad de "custodiar, preservar y expandir el patrimonio cultural y natural, material e inmaterial de la provincia", en adecuación con lo postulado por la Ley Provincial de Patrimonio Cultural (p. 32).

Respecto de esta meta referida al patrimonio, el Plan enuncia una política provincial que, a largo plazo, se centra en "instalar la valoración social (...), a través de campañas de educación y difusión pública orientadas a transmitir la idea de patrimonio como herencia cultural, dada su función social y también como dinamizadora de ciertos sectores de la economía, incluyendo el turismo y el desarrollo urbano". A corto plazo, el plan enfatiza la importancia de implementar la ley de patrimonio cultural y la puesta en marcha de mecanismos culturales para "fomentar y sostener la investigación patrimonial" y "gestionar eficientemente, custodiar, preservar y expandir el patrimonio de la provincia" (p. 73).

Ambos planes, el de turismo y el de cultura, aparecen relacionados en cuanto a los indicadores que cada uno establece para medir la eficacia en la implementación de las políticas culturales. Dentro de los puntos en común, el patrimonio se introduce como un concepto central, vinculado con la identidad puntana que es necesario fortalecer, pero además se contempla la posibilidad de ser utilizado creativamente para el desarrollo sustentable regional desde su dimensión económica y/o turística. Cabe destacar que "la naturaleza" y "el ambiente" son aspectos que tienen un lugar explícito en estos documentos en relación con la necesidad de su preservación, tanto por tratarse de recursos no renovables, como porque definen la identidad puntana y modelan las expresiones culturales (9) (p. 50). Asimismo, se mencionan los aspectos "inmateriales" o la dimensión "intangible" que integra la definición de patrimonio, destacándola como un componente constitutivo fundamental de la vida comunitaria. En este sentido, los recursos culturales de la provincia se entienden desde una perspectiva integral, 
dando cuenta de la diversidad de elementos que, aún resaltados punto por punto, funcionan de modo articulado y requieren ser considerados entre las acciones de gobierno que se planifiquen en este campo.

No obstante, si observamos el repertorio patrimonial de la provincia que surge del listado de declaratorias de bienes culturales, se evidencia un fuerte hincapié en el patrimonio material e inmueble (ver Tabla 3).

\begin{tabular}{|c|c|c|c|}
\hline Zona & Bien Declarado & Categoría & Norma \\
\hline $\begin{array}{l}\text { Santa Rosa de } \\
\text { Conlara }\end{array}$ & $\begin{array}{l}\text { Casa de la Cultura } \\
\text { Zalazar Pringles }\end{array}$ & $\begin{array}{l}\text { Bien de pertenencia al } \\
\text { patrimonio cultural prov. }\end{array}$ & $\begin{array}{l}\text { Decreto 3861- } \\
1992\end{array}$ \\
\hline $\begin{array}{l}\text { San Francisco del } \\
\text { Monte de Oro }\end{array}$ & $\begin{array}{l}\text { Casa de la maestra } \\
\text { Rosenda Quiroga }\end{array}$ & $\begin{array}{l}\text { Bien de interés cultural } \\
\text { provincial }\end{array}$ & $\begin{array}{l}\text { Decreto 729- } \\
1993\end{array}$ \\
\hline Villa de Merlo & $\begin{array}{l}\text { Casa del Poeta Antonio } \\
\text { Esteban Agüero }\end{array}$ & $\begin{array}{l}\text { Bien de pertenencia al } \\
\text { patrimonio cultural } \\
\text { provincial }\end{array}$ & $\begin{array}{l}\text { Decreto 1722- } \\
1993\end{array}$ \\
\hline Leandro N. Alem & $\begin{array}{l}\text { Capilla de Nuestra } \\
\text { Señora del Rosario }\end{array}$ & $\begin{array}{l}\text { Bien de pertenencia al } \\
\text { patrimonio cultural } \\
\text { provincial }\end{array}$ & $\begin{array}{l}\text { Decreto 3391- } \\
1993\end{array}$ \\
\hline San Luis & Palacio Mollo & $\begin{array}{l}\text { Bien de pertenencia al } \\
\text { patrimonio cultural } \\
\text { provincial }\end{array}$ & $\begin{array}{l}\text { Decreto 360- } \\
1994\end{array}$ \\
\hline Justo Daract & $\begin{array}{l}\text { Biblioteca Popular } \\
\text { Domingo F. Sarmiento }\end{array}$ & $\begin{array}{l}\text { Bien de pertenencia al } \\
\text { patrimonio cultural } \\
\text { provincial }\end{array}$ & $\begin{array}{l}\text { Decreto 469- } \\
1994\end{array}$ \\
\hline San Luis & $\begin{array}{l}\text { Colegio (Ex Nacional) } \\
\text { Juan C. Lafinur }\end{array}$ & $\begin{array}{l}\text { Bien de pertenencia al } \\
\text { patrimonio cultural } \\
\text { provincial }\end{array}$ & $\begin{array}{l}\text { Decreto 2524- } \\
1994\end{array}$ \\
\hline San Luis & $\begin{array}{l}\text { Escuela provincial } \mathrm{N}^{\circ} 5 \\
\text { B. Mitre }\end{array}$ & $\begin{array}{l}\text { Bien de pertenencia al } \\
\text { patrimonio cultural } \\
\text { provincial }\end{array}$ & $\begin{array}{l}\text { Decreto 671- } \\
1994\end{array}$ \\
\hline San Luis & $\begin{array}{l}\text { Residencia del Gdor. } \\
\text { Narciso Gutiérrez }\end{array}$ & $\begin{array}{l}\text { Bien de pertenencia al } \\
\text { patrimonio cultural } \\
\text { provincial }\end{array}$ & $\begin{array}{l}\text { Decreto 699- } \\
1994\end{array}$ \\
\hline San Luis & Municipalidad & $\begin{array}{l}\text { Bien de pertenencia al } \\
\text { patrimonio cultural } \\
\text { provincial }\end{array}$ & $\begin{array}{l}\text { Decreto 1899- } \\
1994\end{array}$ \\
\hline San Luis & Esc. $\mathrm{N}^{\circ} 1$ Lafinur & $\begin{array}{l}\text { Bien de pertenencia al } \\
\text { patrimonio cultural } \\
\text { provincial }\end{array}$ & $\begin{array}{l}\text { Decreto 1769- } \\
1995\end{array}$ \\
\hline San Luis & $\begin{array}{l}\text { Escuela No } 14 \text { M. P. } \\
\text { Daract }\end{array}$ & $\begin{array}{l}\text { Bien de pertenencia al } \\
\text { patrimonio cultural } \\
\text { provincial }\end{array}$ & $\begin{array}{l}\text { Decreto 1770- } \\
1995\end{array}$ \\
\hline San Luis & $\begin{array}{l}\text { Colegio } \mathrm{N}^{\circ} 3 \mathrm{M} . \\
\text { Belgrano }\end{array}$ & $\begin{array}{l}\text { Bien de pertenencia al } \\
\text { patrimonio cultural } \\
\text { provincial }\end{array}$ & $\begin{array}{l}\text { Dec. } \\
\text { 1703(1837)1995 }\end{array}$ \\
\hline
\end{tabular}




\begin{tabular}{|c|c|c|c|}
\hline $\begin{array}{l}\text { Ciudad y Pcia. de San } \\
\text { Luis }\end{array}$ & $\begin{array}{l}\text { Escuela Paula } \\
\text { Domínguez de Bazán }\end{array}$ & $\begin{array}{l}\text { Bien de pertenencia al } \\
\text { patrimonio cultural } \\
\text { provincial }\end{array}$ & $\begin{array}{l}\text { Decreto 1949- } \\
1995\end{array}$ \\
\hline Villa Mercedes & $\begin{array}{l}\text { Colegio Juan E. } \\
\text { Pedernera }\end{array}$ & $\begin{array}{l}\text { Bien de pertenencia al } \\
\text { patrimonio cultural } \\
\text { provincial }\end{array}$ & $\begin{array}{l}\text { Decreto 1862- } \\
1995\end{array}$ \\
\hline Villa Mercedes & $\begin{array}{llll}\begin{array}{l}\text { Escuela } \\
\text { Moreno }\end{array} & \mathrm{N}^{\circ} & 31 & \mathrm{M} . \\
\end{array}$ & $\begin{array}{l}\text { Bien de pertenencia al } \\
\text { patrimonio } \\
\text { provincial }\end{array}$ & $\begin{array}{l}\text { Decreto 1967- } \\
1995\end{array}$ \\
\hline $\begin{array}{l}\text { Tramo e/ Rincón del } \\
\text { Este, Merlo y límite } \\
\text { con Córdoba }\end{array}$ & Ruta Provincial $N^{\circ} 5$ & $\begin{array}{l}\text { Valor Turístico e } \\
\text { Histórico Cultural }\end{array}$ & $\begin{array}{l}\text { Ley II 0061- } \\
2004\end{array}$ \\
\hline Territorio provincial & Algarrobo & $\begin{array}{l}\text { Árbol Simbólico } \\
\text { Provincial }\end{array}$ & $\begin{array}{l}\text { Ley II 0050- } \\
2004\end{array}$ \\
\hline Territorio Provincial & $\begin{array}{ll}\text { Libro de } & \text { Autores } \\
\text { Sanluiseños } & \end{array}$ & Bien de Interés Provincial & $\begin{array}{l}\text { Ley II 0513- } \\
2006\end{array}$ \\
\hline $\begin{array}{l}\text { Localidad de San } \\
\text { Pablo }\end{array}$ & Templo de San Pablo & $\begin{array}{l}\text { Patrimonio Cultural } \\
\text { Histórico Provincial }\end{array}$ & $\begin{array}{l}\text { Ley II 0647- } \\
2008\end{array}$ \\
\hline Villa Mercedes & $\begin{array}{l}\text { Sociedad Italiana de } \\
\text { Villa Mercedes }\end{array}$ & Conjunto Histórico & $\begin{array}{l}\text { Ley II 0686- } \\
2009\end{array}$ \\
\hline San Luis & $\begin{array}{l}\text {-Edificio de la ex "Casa } \\
\text { de Gobierno" } \\
\text {-Edificio "Terrazas del } \\
\text { Portezuelo" }\end{array}$ & $\begin{array}{l}\text { Patrimonio Histórico } \\
\text { Cultural Provincial }\end{array}$ & $\begin{array}{l}\text { Ley II 0728- } \\
2010\end{array}$ \\
\hline Concorán & $\begin{array}{l}\text { Iglesia Ntra. Señora de } \\
\text { los Dolores }\end{array}$ & $\begin{array}{l}\text { Patrimonio Cultural } \\
\text { Histórico Provincial }\end{array}$ & $\begin{array}{l}\text { Ley II 0782- } \\
2011\end{array}$ \\
\hline $\begin{array}{l}\text { El paraje La Toma } \\
\text { Vieja del Depto. de } \\
\text { Coronel Pringles }\end{array}$ & Edificio "El Castillo" & $\begin{array}{l}\text { Bien de Interés Histórico } \\
\text { Cultural }\end{array}$ & $\begin{array}{l}\text { Ley II 0753- } \\
2011\end{array}$ \\
\hline Concorán & $\begin{array}{l}\text { Escuela } N^{\circ} 74 \text { Benigno } \\
\text { Rodríguez Jurado }\end{array}$ & Conjunto Histórico & $\begin{array}{l}\text { Ley II 0781- } \\
2011\end{array}$ \\
\hline $\begin{array}{l}\text { Cementerio de la ““El } \\
\text { Volcán”, Depto. Juan } \\
\text { M. de Pueyrredón }\end{array}$ & $\begin{array}{l}\text { Tumba del Cineasta } \\
\text { Gerardo Vallejos }\end{array}$ & $\begin{array}{l}\text { Bien de Interés Histórico } \\
\text { Cultural }\end{array}$ & $\begin{array}{l}\text { Ley II 0784- } \\
2011\end{array}$ \\
\hline Villa Mercedes & $\begin{array}{l}\text { Monumento en } \\
\text { Homenaje al natalicio } \\
\text { del Sr. José M. Gatica }\end{array}$ & $\begin{array}{l}\text { Patrimonio Histórico } \\
\text { Cultural Provincial }\end{array}$ & $\begin{array}{l}\text { Ley II 0846- } \\
2013\end{array}$ \\
\hline Quines & $\begin{array}{l}\text { Chimenea del } \\
\text { Aserradero Santa María }\end{array}$ & $\begin{array}{l}\text { Patrimonio Cultural } \\
\text { Histórico y } \\
\text { Arquitectónico Pcial. }\end{array}$ & $\begin{array}{l}\text { Ley II 0908- } \\
2014 \\
\text { Decreto 9682- } \\
2014\end{array}$ \\
\hline
\end{tabular}

Figura 3. Listado de bienes culturales de San Luis declarados a nivel provincial.

Por último, cabe mencionar los programas que se elaboraron en base a los lineamientos surgidos de los mencionados planes, como es el caso del Programa Cultura, dependiente de la Secretaría General de Gobernación, a través del cual se establece una agenda cultural con diversas actividades relacionadas con talleres sobre 
música, poesía, capacitaciones a artistas en diferentes localidades, muestras de arte, realización de visitas a la réplica del cabildo, entre otras (10). Asimismo, recientemente este programa, a través del Subprograma Patrimonio Histórico y Cultural, ha desarrollado proyectos como el de relevamiento de casas y edificios históricos (11) de la capital provincial -ver el siguiente apartado de ordenanzas municipales, punto A- para generar un inventario que contribuya a la valoración y preservación de ese patrimonio. La puesta en marcha de estas acciones muestra una política de gobierno en la cual el patrimonio cultural integra las prioridades de la gestión provincial. En los últimos años se ha avanzado en la elaboración de un inventario y listado de bienes patrimoniales naturales y culturales, tangibles e intangibles de la provincia, muchos de los cuales han sido declarados mediante normas especiales (ver Tabla 3).

\section{Ordenanzas Municipales}

Para completar el panorama normativo cabe mencionar las competencias municipales sobre el patrimonio cultural que contempla la Constitución Provincial en sus arts. 247, 248 y concordantes y lo dispuesto en la Ley Orgánica Municipal (Leyes 1213-2159, Decreto-Ley 284-GyE-RL-581213-2159). Una característica destacada es que la provincia de San Luis le reconoce autonomía a sus municipios. A su vez, conforme a lo establecido en los arts. 17, 23 inc. d), 75 incs. b) y c), 76 inc. h), 85 inc. b) de la Carta Orgánica Municipal, se establece que los Municipios deben garantizar un medio ambiente equilibrado y salubre, promover la conservación y el enriquecimiento del patrimonio histórico, cultural y artístico. Asimismo, es competente en materia de planeamiento urbano, tomando en consideración los modos de vida y garantizando el racional establecimiento de los asentamientos humanos, fijando pautas para una apropiada densidad de los mismos, su infraestructura y servicios (Endere e Iturburu 2010).

En este marco caben mencionarse algunas de las principales y más recientes ordenanzas de patrimonio cultural sancionadas por los gobiernos locales de la provincia de San Luis, como es el caso de la ciudad de San Luis específicamente. Al respecto se describen brevemente las siguientes:

a) La Ordenanza de Patrimonio Histórico-Cultural de la Municipalidad de San Luis N X-0801-2018 (3496/2018) que adhiere a la Ley Provincial de Patrimonio Cultural, y así también decretos relacionados como el de "Declarar de Interés Municipal el Proyecto de Delimitación Espacial del "CASCO VIEJO" de la ciudad de San Luis, presentado por la Secretaría de Patrimonio Histórico y Cultural (Decreto No 1761SLyT-2017) (12). En este último se destaca que "Los distintos bienes existentes en la Ciudad de San Luis, que por sus características contienen valores de tipo histórico, y/o cultural y/o arquitectónico y/o natural y/o arqueológico, merecen, conforme a la constitución provincial (Art. 68) y la Carta Orgánica Municipal de la ciudad de San Luis (art. 75 y 76), la promoción por parte de los estados de su preservación, 
como de así también de aquellas fachadas e inmuebles que contienen valor histórico, arquitectónico, y cultural de la Ciudad. Que aún existen edificios que cuentan con 100 años o más de antigüedad con características propias de una época pasada y que merecen ser destacados en el ámbito de nuestra Ciudad".

b) La Ordenanza N N $^{\circ}$ 2785-HCD-99.- del Municipio de San Luis por la cual se regula la evaluación de Impacto Ambiental, definido como el estudio encaminado a identificar e interpretar, así como a prevenir las consecuencias o efectos sociales y ambientales que determinadas Acciones, Planes, Programas o Proyectos, pueden causar a la salud y al bienestar humano y al entorno, es decir a los ecosistemas en el que el hombre vive y de lo que depende.

La norma se fundamenta en la necesidad de garantizar el adecuado manejo del ambiente protegiendo los ecosistemas, asegurando las opciones de uso por parte de las generaciones futuras, bajo el concepto de Desarrollo Sustentable. Para ello adopta una política de evaluación de Impacto Ambiental que el Municipio desarrolla en orden a lograr el fin propuesto, la se funda en los siguientes principios: a) Los bienes protegidos por esta Ordenanza, no son susceptibles de ser parcializados en cuanto a su titularidad, por lo que cada habitante es considerado titular de un derecho a un bien indivisible, merecedor de la debida protección legal, en el ámbito de ese Municipio. b) Quienes con su actividad provocan de manera directa o indirecta, un impacto al medio ambiente o social, son responsables de soportar la carga económica derivada de evaluar y minimizar las consecuencias perjudiciales de su actividad.

\section{Conclusiones}

A partir del análisis realizado se pueden efectuar algunas consideraciones generales respecto de la legislación y las políticas culturales de la provincia. En relación con las tres cuestiones que señalamos como claves, es decir la identidad, la participación ciudadana y la sustentabilidad socio-cultural del patrimonio, se evidencia una tendencia creciente a lo largo de los años, particularmente en la última década, a hacerlas explícitas en los documentos analizados, marcando una notable actualización en la temática. No obstante, ese énfasis se vuelve menos claro a la hora de analizar su puesta en práctica, muchas veces debido a la falta de reglamentación de las normas o de implementación de los planes y programas. Un aspecto no menos significativo es que en el sistema de protección del patrimonio cultural de San Luis conviven normativas y mecanismos de protección que responden a diferentes lógicas; mientras algunas se ajustan a las nuevas ópticas (i.e. presentan una visión integral, diversa, plural y participativa del patrimonio), otras mantienen una concepción tradicional, que centra su preocupación casi exclusivamente en la protección de los bienes culturales materiales e inmuebles. Si analizamos los listados de bienes culturales declarados de la provincia se observan dos etapas, la primera que termina en la década de los 90s se muestra una visión del patrimonio tradicional y erudito que pone el eje en el patrimonio arquitectónico e histórico; el listado pone el énfasis en el patrimonio patrio, 
colonial eclesiástico, así como en escuelas y lugares vinculados con poetas locales. A partir de 2004 se evidencia una nueva etapa en la que se comienzan a incluir paisajes de valor turístico (Ruta 5), elementos naturales con valor simbólico (algarrobo), se reconoce el patrimonio inmigrante (Edificio de la Sociedad Italiana), industrial (Chimenea del Aserradero) y del siglo XXI (Terrazas del Portezuelo), aunque siempre manteniendo el énfasis en los valores históricos y arquitectónicos. En relación a los bienes arqueológicos, cabe destacar que la provincia en 2004 declaró un listado de yacimientos con arte rupestre como bienes culturales, pero luego no se volvieron a incluir sitios arqueológicos en ninguna otra declaratoria, pese al crecimiento sostenido de las investigaciones en la provincia en la última década y la consiguiente identificación de nuevos sitios.

Cabe señalar además que no existen declaratorias vinculadas con el patrimonio intangible. De alguna manera podría afirmarse que persiste la tendencia a poner el énfasis en el patrimonio material sin considerar los componentes inmateriales y la dimensión humana.

Otra característica relevante de estas políticas es el claro interés en vincular el patrimonio cultural con la identidad puntana como un mecanismo para contribuir a su fortalecimiento. Esto se hace más evidente en épocas recientes en donde las disposiciones legales apuntan a la generación de programas que hacen hincapié en la "puntanidad", al tiempo que reconocen la diversidad cultural propia de la provincia y la inclusión de diferentes actores, en particular las comunidades indígenas Ranquel y Huarpe, por su carácter de preexistentes. No obstante, se presupone la adhesión comunitaria a las actividades culturales y la identificación con la identidad local sin mensurar su verdadero grado de implicación. Los destinatarios de estas políticas siguen siendo una abstracción, sin que se contemplen mecanismos específicos de participación. Sin embargo, debe destacarse el rol activo de asociaciones locales y algunos actores destacados del ámbito cultural, los cuales no sólo tienen visibilidad pública, sino que están efectuando también acciones conjuntas con diferentes instancias de gobierno (e.g. iniciativas relativas a la protección del Casco Viejo de San Luis).

En este marco, discutir la sustentabilidad sociocultural del patrimonio genera el desafío para sus gestores de evaluar aspectos que permitan medir su alcance y que contribuyan a fortalecerla. Por ejemplo, una herramienta factible sería la construcción de indicadores en base al estudio de factores vinculados con la acción pública en relación a esta temática, teniendo en cuenta la función pluridimensional de la cultura y del patrimonio en los procesos de desarrollo. En este sentido sería interesante explorar posibles cuestiones a considerar, tales como la accesibilidad física e intelectual al patrimonio (es decir, en qué grado sus destinatarios acceden al patrimonio); las percepciones comunitarias (qué sentido y valor le dan al patrimonio), las acciones de educación y sensibilización (qué acciones se realizan; con qué frecuencia y alcance; cuál es el impacto). Asimismo, sería relevante evaluar la participación en instancias de 
gestión que involucren algún tipo de toma de decisiones; así como la capacidad de autogestión comunitaria para generar emprendimientos culturales que tengan por objeto el patrimonio cultural y de sostenerlos en el tiempo, entre otros aspectos.

Llevar a cabo estas instancias de evaluación requiere trabajar con comunidades relativamente pequeñas, grupos de interés seleccionados o ciudadanos involucrados en proyectos concretos. Aunque complejas, estas instancias son de gran utilidad para identificar dificultades, así como potencialidades de la gestión patrimonial y ofrecer una plétora de información empírica sustancial para orientar de manera continua la práctica de la gestión en vista a la sustentabilidad sociocultural del patrimonio.

Por último, reflexionar acerca del patrimonio en relación a cuestiones como la participación ciudadana y la sustentabilidad sociocultural no deja de ser una inquietud relativamente reciente y, por ende, poco explorada en los sistemas de protección legal del patrimonio en los gobiernos provinciales. San Luis ha sido pionera en la incorporación de estas nuevas temáticas, abriendo un abanico de desafíos a la hora de su implementación. Construir indicadores para evaluarlas puede generar una vía para avanzar hacia su concreción.

Agradecimientos: Se agradece a los funcionarios que aportaron documentación con la cual se ha efectuado parte de esta investigación. Este trabajo fue realizado en el marco de las investigaciones desarrolladas por PATRIMONIA (Programa Interdisciplinario de Estudios del Patrimonio), INCUAPA (U.E. CONICET - UNICEN), financiado a través del proyecto PICT 0551/16, dirigidos por María Luz Endere y financiado por la ANPCyT y derivados de la investigación posdoctoral de la becaria María Vanesa Giacomasso.

\section{Notas}

1. Cabe aclarar que se entenderá por políticas públicas al diseño de acciones colectivas e intencionadas que un gobierno define para alcanzar determinados objetivos; por plan al conjunto de fines y reglas dentro del cual se enmarcan los programas y proyectos. Los programas operacionalizan un plan mediante la realización de acciones orientadas a alcanzar las metas y objetivos propuestos dentro de un período determinado e incluyen varios proyectos. Estos últimos implican al conjunto de actividades concretas, interrelacionadas y coordinadas entre sí que se llevan a cabo desde una gestión de gobierno (Martínez Nogueira 2010).

2. Nota online http://agenciasanluis.com/notas/2013/10/08/desarrollan-programasde-valorizacion-del-patrimonio/

3. Esta cuestión del tratamiento de los medios sobre el tema del patrimonio cultural es también objeto de investigación, el cual forma parte de otros análisis complementarios que no serán incluidos en este artículo.

4. En 2014 se presentó en el Senado de la Nación un proyecto de ley para declarar bien histórico-artístico del patrimonio cultural de la Nación, en los términos de la ley 12.665, los yacimientos con arte rupestre ubicados en los departamentos de la provincia de San 
Luis que ya habían sido declarados a nivel provincial mediante la ley No II-0062-2004 (5740) (Ref. leg. S-0673/14). De haber prosperado este proyecto se hubiera declarado a nivel nacional el sitio Inti Huasi.

5. La zona de las Lagunas de Guanacache ha sido incluida dentro de la declaratoria de Sitio RAMSAR (Lagunas de Guanacache, Desaguadero y del Bebedero, noreste de Mendoza, sudeste de San Juan y noroeste de San Luis).

6. Ver Constitución Provincia de San Luis. Texto aprobado por la Honorable Convención Reformadora de la Provincia de San Luis, en sesión pública del 26/03/87 con enmiendas de los artículos 147 y 11 Bis, realizadas respectivamente por las leyes $\mathrm{N}^{\circ}$ XIII-0545-2006 y No XIII-0755-2011 (BO de la provincia de San Luis 13820 del 11/11/11). Sitio web: http:/ministerios.sanluis.gov.ar/res/5088/media/pdf/19589.pdf 7. Dentro de este eje "industrias creativas" en el documento se destacan algunas metas como las de promover el desarrollo de la industria del libro, de la industria audiovisual y el cine, de la música, los Servicios Informáticos y la industria del turismo, entre otras cosas (p. 82).

8. El concepto de puntanidad o lo puntano proviene de la denominación de "La Punta" o "Punta de los Venados" como una designación geográfica que alcanzaba en un principio a los habitantes de la ciudad de San Luis y posteriormente a todo el territorio provincial, por el hecho de estar emplazada en el extremo sur del cordón montañoso llamado "Sierras de San Luis".

9. Dentro de esta iniciativa se plantean acciones de protección ambiental a través de lo que se denomina el "arte ecológico", en el cual se trata de generar conciencia en la sociedad acerca del valor de los espacios naturales y los ecosistemas, utilizando materiales naturales, no contaminantes o reciclables.

10. Ver más información en

https://culturasanluis.com/?fbclid=IwAR1EZF0ko0qObRY8VAw9mGbf-

SZGn1GnU0uyZaMXEzeXdkS6_NK4nY3s_MA

11. Nota online: https://www.eldiariodelarepublica.com/nota/2018-8-8-19-11-0proyecto-de-relevamiento-de-casas-historicas

12. Ver: https://www.ciudaddesanluis.gov.ar/?q=Casco\%20Viejo

\section{Bibliografía Citada}

Berberián, E.

2009 La protección del patrimonio cultural argentino. Arqueológico y paleontológico. La ley nacional $N^{0}$ 25.753. Comentarios al texto. Editorial Brujas, Córdoba.

Bonfil Batalla, G.

2004 Pensar nuestra cultura. Nuestro patrimonio cultural: un laberinto de significados.

Diálogos en la acción 1: 117-134.

Calabrese, A.

2012 La protección del patrimonio cultural argentino. Arqueológico y paleontológico. Lumière, Buenos Aires. 
Caraballo Perichi, C.

2012 El patrimonio cultural y la gestión participativa: ejercicio incompleto de los derechos de la ciudadanía. Revista de derechos humanos 6: 19-23.

Endere, M.

2009 Algunas Reflexiones acerca del Patrimonio. En Patrimonio, Ciencia y Comunidad. Su abordaje en los Partidos de Azul, Tandil y Olavarría, M. L. Endere y J. Prado (Edit.), pp. 1948. UNCPBA, Olavarría.

Endere, M. y L. Colombato

2017 The new Unified Civil and Commercial Code and Cultural Heritage Protection in Argentina. International Journal of Cultural Property 24: 79-99.

Endere, M. y M. Iturburu

2010 La protección del patrimonio cultural en los municipios argentinos. Revista Jurídica 5: 13-37.

Endere, M. L. y J. L. Prado

2009 Criterios de selección, valorización y zonificación de yacimientos arqueológicos y paleontológicos. En Patrimonio, ciencia y comunidad. Un abordaje preliminar en los partidos de Azul, Olavarría y Tandil, L. Endere y J. L. Prado (Edit.), pp. 49-66. UNCPBA, Olavarría.

Endere, M. y D. Rolandi

2007 Legislación y gestión del patrimonio arqueológico. Breve reseña de lo acontecido en los últimos 70 años. Relaciones de la Sociedad Argentina de Antropología 32: 33-54.

Endere, M. L. y L. Zulaica

2015 Sustentabilidad socio-cultural y buen vivir en sitios patrimoniales: evaluación del caso Agua Blanca, Ecuador. Ambiente E Sociedade 18 (4): 265-290.

García Canclini, N.

1999 Los usos sociales del patrimonio cultural. En Patrimonio etnológico. Nuevas perspectivas de estudio, E. Aguilar Criado (Ed.), pp.16-33. Consejería de la Cultura, Sevilla.

García, D. y G. Priotto

2008 La sustentabilidad como discurso ideológico. Programa de Estrategia Nacional de Educación Ambiental, SAySD, Buenos Aires.

Giacomasso, V. y M. Endere

2016 El Patrimonio Cultural de San Luis. Reflexiones acerca de la normativa legal que promueve su salvaguarda. Andes: Historia y Antropología 26 (2): 1-24. 
Giménez, G.

2005 Patrimonio e identidad frente a la globalización. Cuadernos del Patrimonio Cultural y Turismo 13: 177-182.

Guimarães, R.

2003 Tierra de sombras: Desafíos de la sustentabilidad y del desarrollo territorial y local ante la globalización corporativa. Serie Medio Ambiente, División de Desarrollo Sostenible y Asentamientos Humanos, 67. CEPAL, Santiago de Chile.

Guráieb, A. y M. Frère

2008 Caminos y encrucijadas en la gestión del patrimonio arqueológico argentino Buenos Aires: Editorial de la Facultad de Filosofía y Letras. Universidad de Buenos Aires.

Prats, LL.

2005 Concepto y gestión del patrimonio local. Cuadernos de Antropología Social 21: 17-35.

Prats, LL.

2007 Antropología y Patrimonio. Editorial Ariel, Barcelona.

Rosas Mantecón, A.

1998 El patrimonio cultural. Estudios contemporáneos. Presentación. Alteridades 16: 3-9.

Rosas Mantecón, A.

2005 Las disputas por el patrimonio. Transformaciones analíticas y contextuales de la problemática patrimonial en México. En La antropología urbana en México, N. García Canclini (Ed.), pp. 60-95. Fondo de Cultura Económica. Universidad Autónoma Metropolitana, México.

\section{UNESCO}

2014. Indicadores UNESCO de cultura para el desarrollo, UNESCO, París.

Wood, S. L. R., S. K. Jones, J. A. Johnson

2018 Distilling the role of ecosystem services in the Sustainable Development Goals. Ecosystem Services, 29: 70-82. 